\title{
Structures, Fragmentation, and Protonation of Trideoxynucleotide CCC Mono- and Dianions
}

\author{
Janna Anichina, ${ }^{a}$ Stefan Feil, ${ }^{\mathrm{a}}$ Einar Uggerud, ${ }^{\mathrm{b}}$ and Diethard K. Bohme ${ }^{\mathrm{a}}$ \\ ${ }^{a}$ Department of Chemistry and Centre for Research in Mass Spectrometry, York University, Toronto, \\ Ontario, Canada \\ ${ }^{b}$ Massespektrometrilaboratoriet og Senter for teoretisk og beregningsbasert kjemi (CTCC), Kjemisk institutt, \\ Universitetet i Oslo, Oslo, Norway
}

Both quantum chemical calculations and ESI mass spectrometry are used here to explore the gas-phase structures, energies, and stabilities against collision-induced dissociation of a relatively small model DNA molecule-a trideoxynucleotide with the sequence $\mathrm{CCC}$, in its singly and doubly deprotonated forms, $(\mathrm{CCC}-\mathrm{H})^{-}$and $(\mathrm{CCC}-2 \mathrm{H})^{2-}$, respectively. Also, the gas-phase reactivity of these two anions was measured with $\mathrm{HBr}$, a potential proton donor, using an ESI/SIFT/QqQ instrument. The computational results provide insight into the gas-phase structures of the electrosprayed $(\mathrm{CCC}-2 \mathrm{H})^{2-}$ and $(\mathrm{CCC}-\mathrm{H})^{-}$anions and the neutral CCC, as well as the proton affinities of the di- and monoanions. The dianion (CCC $2 \mathrm{H})^{2-}$ was found to dissociate upon $\mathrm{CID}$ by charge separation via two competing channels: separation into deprotonated cytosine $(\mathrm{C}-\mathrm{H})^{-}$and $(\mathrm{CCC}-(\mathrm{C}-\mathrm{H})-2 \mathrm{H})^{-}$, and by $\mathrm{w}_{1}^{-} / \mathrm{a}_{2}^{-}$ cleavage of the backbone. The monoanion $(\mathrm{CCC}-\mathrm{H})^{-}$loses a neutral cytosine upon $\mathrm{CID}$, and an $\mathrm{H} / \mathrm{D}$-exchangeable proton, presumably residing on one of the phosphate groups, is transferred to the partially liberated $(\mathrm{C}-\mathrm{H})^{-}$before dissociation. This was confirmed by MS/MS experiments with the deuterated analog. The reaction of $(\mathrm{CCC}-2 \mathrm{H})^{2-}$ with $\mathrm{HBr}$ was observed to be rapid, $\mathrm{k}=(1.4 \pm 0.4) \times 10^{-9} \mathrm{~cm}^{3}$ molecule ${ }^{-1} \mathrm{~s}^{-1}$, and to proceed both by addition $(78 \%)$ and by proton transfer $(22 \%)$ while $(\mathrm{CCC}-\mathrm{H})^{-}$reacts only by $\mathrm{HBr}$ addition, $\mathrm{k}=(7.1 \pm 2.1) \times 10^{-10} \mathrm{~cm}^{3}$ molecule $\mathrm{e}^{-1} \mathrm{~s}^{-1}$. This is in accord with the computed proton affinities of $(\mathrm{CCC}-2 \mathrm{H})^{2-}$ and $(\mathrm{CCC}-\mathrm{H})^{-}$anions that bracket the known proton affinity of $\mathrm{Br}^{-}$. (J Am Soc Mass Spectrom 2008, 19, 987-996) (C 2008 American Society for Mass Spectrometry

$\mathrm{T}$ The advent of electrospray ionization (ESI) [1,2] has spawned remarkable advances in the structural characterization of biomolecules, including DNA, RNA, and oligodeoxy/ribonucleotides, as well as their metallated adducts and noncovalent complexes with proteins and drugs [3-15]. Both positive and negative gas-phase ions of oligodeoxynucleotides can now be formed at will, covering a range of charge states according to chosen electrospray conditions. Collisioninduced dissociation (CID) has proven to be a powerful tool for discerning important information about nucleobase sequences of oligonucleotides and probable sites for the binding of metal ions. Several mechanisms have been suggested for the dissociation of single-stranded oligodeoxynucleotides by base loss and cleavage of the phosphodiester backbone $[3,5,11]$. However, no single mechanism appears to be consistent with all observations. More information is needed about the influence of the nature of the base, its location, the charge state of the oligodeoxynucleotide, and its length. Here we focus on the influence of charge state for a homogeneous

Address reprint requests to Dr. D. K. Bohme, Department of Chemistry and Centre for Research in Mass Spectrometry, York University, 4700 Keele Street, Toronto, Ontario, Canada M3J 1P3. E-mail: dkbohme@yorku.ca trideoxynucleotide. Trideoxynucleotides are the smallest groups of nucleotides in DNA (codons) that determine which amino acids will be inserted in given positions in a polypeptide chain. For instance, CCC codes for the proline amino acid. Both quantum theory and ESI-MS experiments are used here to explore the gas-phase structures, energies, and stabilities against collision-induced dissociation of an oligodeoxynucleotide with the sequence $\mathrm{CCC}$, in its singly and doubly deprotonated forms, $(\mathrm{CCC}-\mathrm{H})^{-}$and $(\mathrm{CCC}-2 \mathrm{H})^{2-}$, respectively.

Another exciting opportunity that has become available with the advent of ESI is the probing of intrinsic chemical properties of DNA-type ions by exposing them to chemical reactions in the gas phase. For example, oligodeoxynucleotides can be deprotonated in solution, sprayed into the gas phase, and then reprotonated by reaction with a suitable proton donor. In our laboratory, we have coupled an electrospray ion source to a selectedion flow tube/triple quadrupole (SIFT/QqQ) mass spectrometer [16] that allows the quantitative measurement of rate coefficients and product distributions for gas-phase chemical reactions of deprotonated oligodeoxynucleotide anions with gases or vapors of liquids, and we report here on the reactions of deprotonated 
CCC with hydrogen bromide. The results of these experiments also allow an assessment of the proton affinities of the singly and doubly deprotonated trideoxynucleotide that are predicted by computations.

\section{Experimental}

Electrospray data were acquired in the negative ion mode using an API 2000 (MDS-SCIEX, Concord, ON, Canada) triple quadrupole $\left(Q_{1} q_{2} Q_{3}\right)$ mass spectrometer equipped with a "TurboIon Spray" ion source. Experiments were performed at an ionspray voltage of -5500 $\mathrm{V}$, a ring-electrode potential of $-300 \mathrm{~V}$ (used for ion beam confinement). $\mathrm{N}_{2}$ was used as a curtain gas at a setting of $70 \mathrm{kPa}$, and air was used as nebulizer gas at a flow rate of $8 \mathrm{~L} \mathrm{~min}{ }^{-1}$. Samples were directly infused into the electrospray source at a flow rate of $3 \mu \mathrm{L}$ min- 1 . MS/MS experiments were carried out in the product ion and multiple reaction monitoring (MRM) modes with $\mathrm{N}_{2}$ as collision gas at a pressure estimated to be about $400 \mathrm{~Pa}$ (viz. multicollision conditions). The collision offset voltage (the potential difference between the quadrupole entrance lens $\left(q_{0}\right)$ and the collision cell quadrupole $\left(q_{2}\right)$, which nominally gives the laboratory frame collision voltage, was adjusted between -1 and $-130 \mathrm{~V}$ at $1 \mathrm{~V}$ intervals. Space charge and contact potentials, field penetration, and field distortion can influence the actual collision energy, but were not taken into account. The zero of energy was not determined with high accuracy. Product ion spectra were then obtained by scanning $Q_{3}$ over the range $\mathrm{m} / \mathrm{z} 10-1700$. The interquadrupole lens potentials and the float potential of the resolving quadrupole $Q_{3}$ were linked to the $q_{2}$ potential to maintain proper transmission through $Q_{3}$. The onset voltage of a particular primary dissociation was determined by extrapolating the steepest slope of a plot of the sum of the relative intensities of the primary dissociation product and all its second and higher generation fragments (Figure 1). The precision of the onset voltage is taken to be one standard deviation from the mean onset voltage value obtained in several

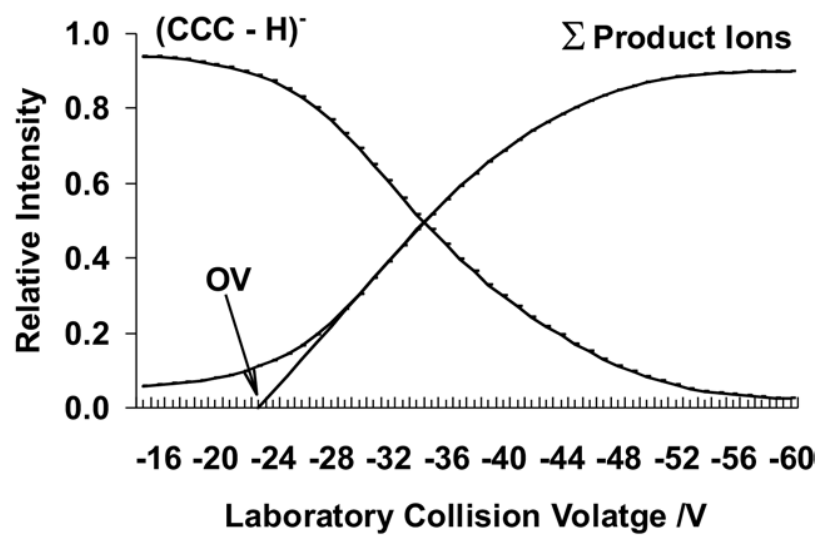

Figure 1. Onset voltage (OV) determination for the collision induced dissociation of $(\mathrm{CCC}-\mathrm{H})^{-}$. (four or more) repeated experiments. In each experiment, Gaussian smoothing was applied twice to the ion signals measured at each collision voltage, each accumulated for a dwell time of $200 \mathrm{~ms}$, to smooth out random noise.

In the preparation of sample solutions, CCC was dissolved in a 80:20 (\%) water/methanol mixture at a concentration of $10 \mu \mathrm{M}$. HPLC degree methanol and Millipore $(18.2 \mathrm{~m} \Omega)$ water were used to prepare the solvent mixtures. $\mathrm{CH}_{3} \mathrm{OD}$ purchased from Sigma-Aldrich and heavy water of $99.75 \%$ purity were utilized for the preparation of the solvent mixture in H/D exchange in solution.

All of the measurements of the gas-phase chemical reactivity of $\mathrm{CCC}$ anions with $\mathrm{HBr}$ were obtained using the ESI/SIFT/QqQ tandem mass spectrometer in accordance to a procedure that has been described in detail recently [16]. Ions were selected according to their $\mathrm{m} / \mathrm{z}$ value with a quadrupole mass filter and injected through an aspirator-like interface into the flow tube, continuously flushed with helium buffer gas at $0.35 \pm$ 0.01 torr and $295 \pm 2 \mathrm{~K}$. The ions undergo $\sim 10^{5}$ collisions with $\mathrm{He}$ atoms before entering the reaction region of the flow tube and this ensures that they have reached a translational temperature equal to the tube temperature of $295 \pm 2 \mathrm{~K}$ before reacting with $\mathrm{HBr}$. $\mathrm{HBr}$ vapor was diluted in He gas in a reservoir system and introduced via a needle valve into the reaction region of the flow tube. Downstream of the reaction region, a second quadrupole mass filter was used to monitor the intensities of reactant and product ions as a function of the flow of $\mathrm{HBr}$. Rate coefficients for the primary reactions of the reactant ions with $\mathrm{HBr}$ are determined with an uncertainty of $\sim 30 \%$ from the rate of decay of the reactant ion intensity assuming pseudo-first-order kinetics. $\mathrm{HBr}(99+\%)$ was obtained from Sigma-Aldrich Co. and used without further purification.

\section{Computational Procedure}

The search for the most stable conformer/stereoisomer (note that protonation of a phosphate group generates a chiral centre at $\mathrm{P}$ ) of each of the following molecules: $(\mathrm{CCC}-2 \mathrm{H})^{2-}, 5^{\prime}(\mathrm{CCC}-\mathrm{H})^{-}, 3^{\prime}(\mathrm{CCC}-\mathrm{H})^{-}$, and CCC was done in a hierarchical fashion employing four methods, which in reverse order of complexity and accuracy are: AMBER8 (molecular mechanics) [17, 18], PM3 (semi-empirical) [19], RI-BP-86/SVP (density functional, small basis set) [20-23], and RI-MP2/TZVPP (Møller-Plesset perturbation theory to second-order) [24, 25]. For each stereoisomer, an initial geometry was constructed by employing the routine xLeap of AMBER8 with standard settings. Force field parameters were taken from the $\mathrm{f} 99$ force field. For nucleotides with a protonated phosphate group the force fields were constructed in accordance to the general description given on the AMBER web pages with slight modifications. The initially constructed geometry was subject to energy minimization, whereupon it was used to gener- 


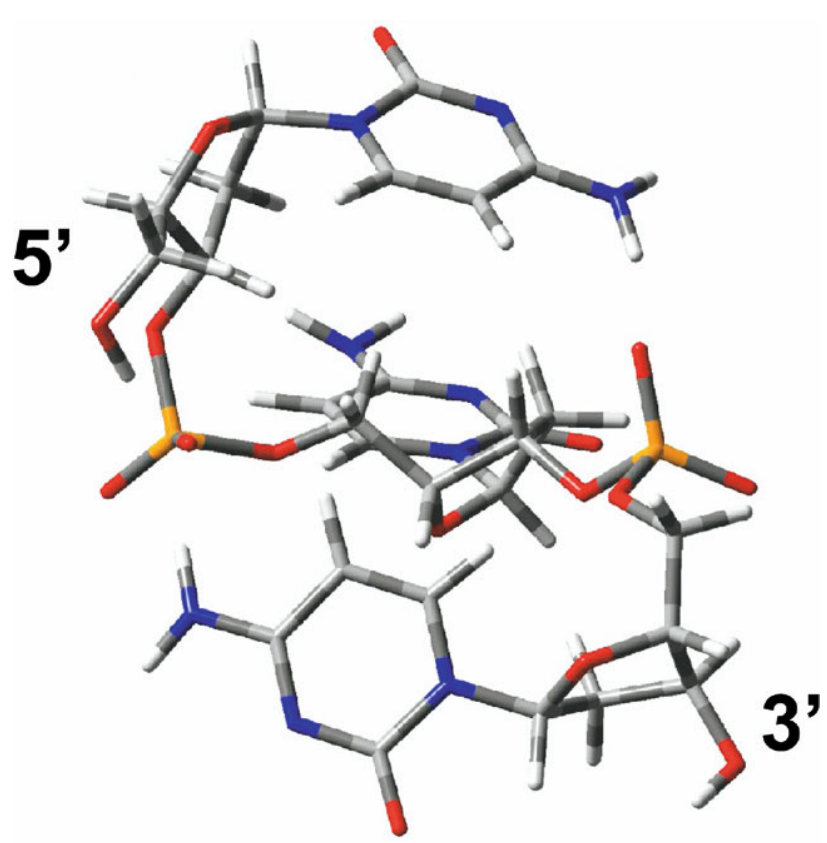

Figure 2. Minimum energy structure of $(\mathrm{CCC}-2 \mathrm{H})^{2-}$. Color code: $\mathrm{P}$, orange; $\mathrm{O}$, red; $\mathrm{N}$, blue; $\mathrm{C}$, grey; $\mathrm{H}$, white. $5^{\prime}$ and $3^{\prime}$ designate the two ends of $(\mathrm{CCC}-2 \mathrm{H})^{2-}$.

ate the starting configuration for a subsequent $0.1 \mathrm{~ns}$ molecular dynamics run at $500 \mathrm{~K}$ using the procedure Sander. A total of 8 to 12 nuclear configurations from each run were sampled, half at random, and half by picking those of lowest potential energy. It was noted that in some cases spontaneous inversion occurred at one or several carbon atoms of the deoxyribose ring. This unwanted and unrealistic behavior occurred despite an effort to avoid it by defining improper dihedral angles. In these cases, the configuration was restored to the natural chirality. Each sampled configuration was then subject to full geometry optimization using the PM3 routine of Gaussian 03 [26]. In addition to the configurations coming out of these molecular dynamics simulations, a comparable number of configurations were generated by starting from the configuration of a
CGC trinucleoside segment, as it appears in a DNA duplex, after substitution of the $\mathrm{G}$ with a $\mathrm{C}$. From this starting point, one, two, or three of the dihedral angles of the oligonucleotide backbone were changed at random, and then subject to PM3 geometry optimization. The resulting structure was then subject to the same procedure, a procedure that was repeated up to eight times for each stereoisomer. Further analysis and manipulation of the intramolecular hydrogen bond network of the PM3 local minimum energy structures of lowest energy lead to even more candidates, which were then for geometry optimizations. The resulting dataset of PM3 minima consists of a total of 160 structures, of which several are identical. For each of the four molecules $(\mathrm{CCC}-2 \mathrm{H})^{2-}, 5^{\prime}(\mathrm{CCC}-\mathrm{H})^{-}, 3^{\prime}(\mathrm{CCC}-\mathrm{H})^{-}$, and $\mathrm{CCC}$ the lowest energy conformers were subject to final and full geometry optimization with RI-BP-86/ SVP as implemented in the TURBOMOLE package [27]. For the doubly and singly negatively charged species, the order of stability of the conformers investigated turned out to be the same for both PM3 and RI-BP-86/SVP. For the neutral molecule, CCC, several of the lowest energy conformers were extremely close in energy, and the energy order between PM3 and RI-BP-86/SVP varied somewhat. Each of the lowest energy RI-BP-86/SVP configurations was finally subjected to single point calculation utilizing RI-MP2/TZVPP, again taking advantage of the TURBOMOLE code.

To model the acid/base properties of the isolated phosphate group, we conducted calculations for phosphoric acid $\left(\mathrm{H}_{3} \mathrm{PO}_{4} / \mathrm{H}_{2} \mathrm{PO}_{4}^{-}\right)$at the same levels of theory as for the DNA fragments. For calibration purposes-in particular to obtain an accurate estimate of the proton affinity-we also applied the G3 method [28] incorporated in Gaussian 03 to this pair of molecules. To obtain an estimate of the strength of a hydrogen bond between a protonated phosphate group and a nonprotonated phosphate group, RI-MP2/TZVPP/ / RI-BP-86/SVP calculations were done for the dimethyl ether of phospho-
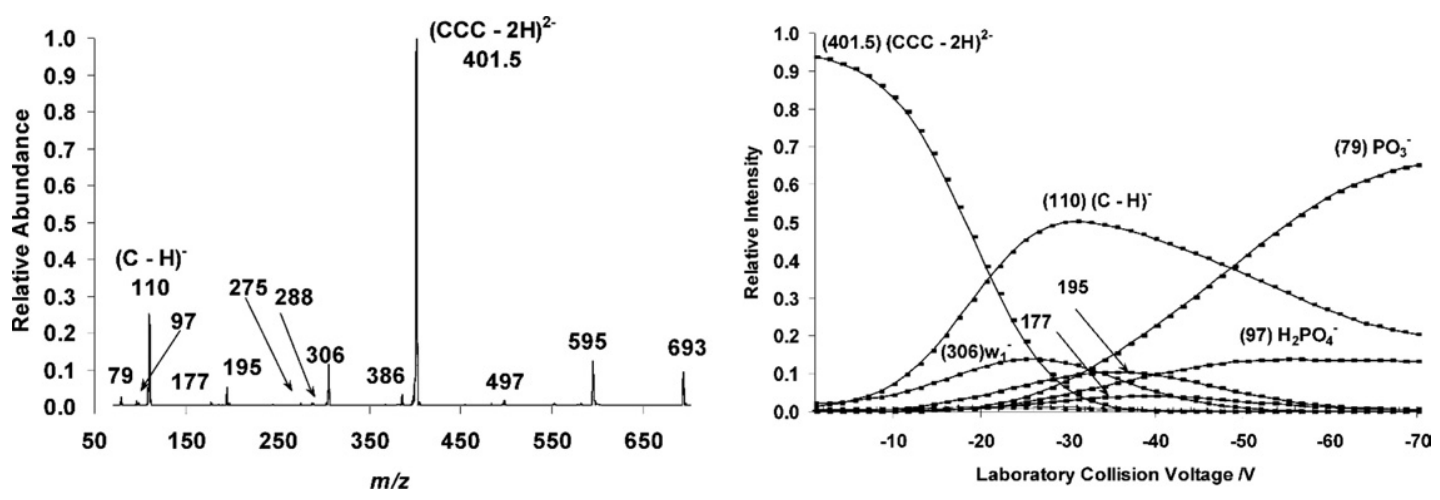

Figure 3. The MS/MS spectrum for the dissociation of $m / z 401.4(\mathrm{CCC}-2 \mathrm{H})^{2-}$ averaged over the region from -1 to $-30 \mathrm{~V}$ (on the left) and CID profiles for this dissociation (on the right). The profiles of the product ions with relative intensities lower than 0.02 , e.g., those for $m / z=693,595,497,386,288$, and 275 , are not shown. 


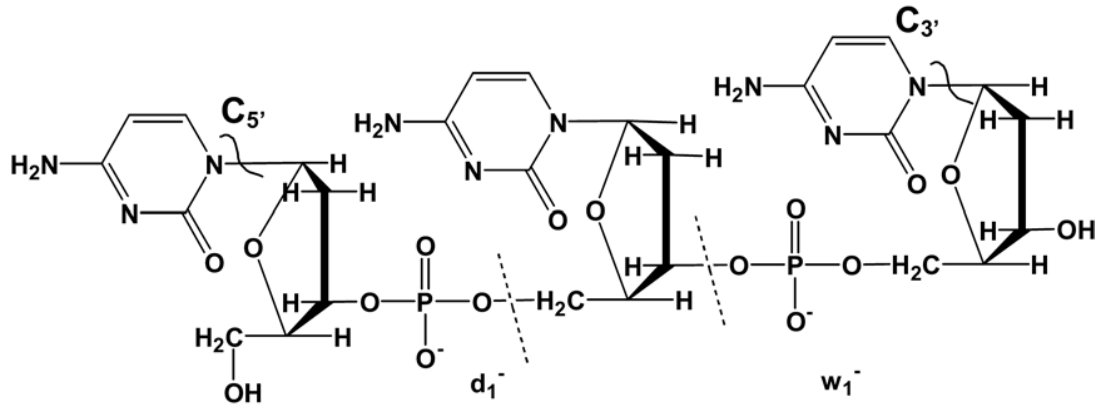

Scheme 1

ric acid, $\mathrm{HOP}(\mathrm{O})\left(\mathrm{OCH}_{3}\right)_{2}$, its corresponding base, and the dimer of the acid and base forms.

\section{Results and Discussion}

The Dianion $(\mathrm{CCC}-2 \mathrm{H})^{2-}$

(a) Structural details. The minimum energy structure of $(\mathrm{CCC}-2 \mathrm{H})^{2-}$ is presented in Figure 2. It is evident that the preferred conformation to a large degree is dictated by the two phosphate groups. First, Coulomb repulsion imposes the two negatively charged phosphate groups to stay away from each other. Second, the hydrogen bond accepting ability of a phosphate group steers attractive interactions with other atom groups in the molecule. These two tendencies reduce the number of possible conformers significantly, a situation which turned out to simplify the search for the global potential energy minimum for this large molecule. In the found minimum energy structure, the phosphate group of the 5' end accepts two hydrogen bonds (one from the $5^{\prime}$-terminal hydroxy group and one from one of the amino hydrogens of the $3^{\prime}$-terminal cytosine; in addition a weak coordination from the slightly acidic 6-H of the central cytosine ring to one of the slightly basic ether oxygens, (P)-O-(C), of the phosphate is observed), while the phosphate group of the $3^{\prime}$ end accepts one $\mathrm{H}$ bond (from one of the amino hydrogens of the 5 '-terminal; in addition, a weak coordination from $6-\mathrm{H}$ of the $3^{\prime}-$ terminal cytosine ring to one of the ether oxygens of the phosphate is observed also in this case).

(b) Pathways for collision induced dissociation. CID performed on the selected dianion $(\mathrm{CCC}-2 \mathrm{H})^{2-}$ indicates that this ion dissociates by charge separation via two competing channels (see Figure 3): (a) formation of a deprotonated cytosine $(\mathrm{C}-\mathrm{H})^{-}$and its complementary fragment, and (b) backbone cleavage leading to the formation of either $\mathrm{w}_{1}^{-}$and $\mathrm{a}_{2}^{-}$or $\mathrm{d}_{1}^{-}$and $\mathrm{z}_{2}^{-}$ions (McLuckey nomenclature [3]). The latter two pairs of ions cannot be distinguished in this experiment since they have identical sets of $m / z$ values. The relative abundance of channel (a) and (b) is $48 \% \pm 2 \%$ and $52 \% \pm 2 \%$, respectively. The efficiencies of the indicated dissociation pathways were obtained by extrapolating normalized abundance of the two channels to $0 \mathrm{~V}$ of the laboratory collision voltage. Scheme $\mathbf{1}$ indicates likely sites for the backbone cleavage.

From Table 1 it can be inferred that the two dissociation channels have similar OV values, with the base elimination (a) at $-4.3 \mathrm{~V}$ (for $m / z 110$ and 693) and the backbone cleavage (b) at $-4.7 \mathrm{~V}$ (for $\mathrm{m} / \mathrm{z} 306$ and 497). Moreover, the two complementary fragment ions appear at the same OV value within experimental uncertainty, a fact that confirms our mechanistic interpretation of charge separation being in operation.

We will be careful not to speculate too widely on the detailed mechanisms of the observed reactions, so all details of Schemes $\mathbf{2}$ to $\mathbf{5}$ should not be taken literally. However, the mechanisms of the primary reactions observed here appear to be well understood. One slight limitation is that we are not sure whether route (b) occurs according to the $\mathrm{w}_{1}^{-} / \mathrm{a}_{2}^{-}$or to the $\mathrm{d}_{1}^{-} / \mathrm{z}_{2}^{-}$fragmentation. From the literature [3, 29], there is strong evidence in favor of the former alternative in similar molecules, so we will assume the $\mathrm{w}_{1}^{-} / \mathrm{a}_{2}^{-}$fragmentation route as our working hypothesis for the rest of the mechanistic discussion.

For route (a) it has been proposed [30] that the loss of a base side group, in the present case $(\mathrm{C}-\mathrm{H})^{-}$, is assisted by the attack of a phosphate group on the deoxyribose ring. This can occur in two ways, either by a nucleophilic attack on the carbon atom that is bonded to the ring nitrogen $(\mathrm{N} 1)$, in which case the $(\mathrm{C}-\mathrm{H})^{-}$ fragment is expelled directly via an $S_{N} 2$ mechanism, or

Table 1. Onset voltages (in volts) for the primary, secondary, tertiary, etc. products for the dissociation of $(\mathrm{CCC}-2 \mathrm{H})^{2}$

\begin{tabular}{lcccccc}
\hline $\mathrm{m} / \mathrm{z}$ & 110 & 693 & 595 & 497 & 306 & 386 \\
$\mathrm{OV} / \mathrm{V}$ & $-(4.2 \pm 0.2)$ & $-(4.3 \pm 0.3)$ & $-(5.5 \pm 0.2)$ & $-(4.8 \pm 0.2)$ & $-(4.5 \pm 0.3)$ & $-(6.3 \pm 0.2)$ \\
$\mathrm{m} / \mathrm{z}$ & 288 & 275 & 195 & 177 & 97 & 79 \\
$\mathrm{OV} / \mathrm{N}$ & $-(6.4 \pm 0.3)$ & $-(10.5 \pm 0.2)$ & $-(15.8 \pm 0.3)$ & $-(15.8 \pm 0.3)$ & $-(19.4 \pm 0.2)$ & $-(17.6 \pm 0.4)$ \\
\hline
\end{tabular}




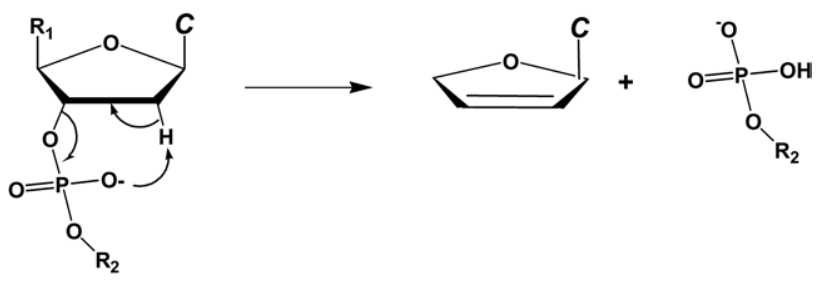

also have to take into account the probability of an attack from a remote phosphate, so not even loss of this side group can be ruled out.

A similar mechanistic scenario can also be envisaged for route (b). We apply the Rodgers/Beauchamp [31] mechanism for $\mathrm{w}^{-} / \mathrm{a}^{-}$backbone cleavage as illustrated in the lower part of Scheme 2. The direct relationship and competition between the Cerny and Rodgers/ Beauchamp dissociation mechanisms is evident. While the $\mathrm{w}_{1}^{-} / \mathrm{a}_{2}^{-}$dissociation in $(\mathrm{CCC}-2 \mathrm{H})^{2-}$ leads to favorable charge division, the corresponding $\mathrm{w}_{2}$ dissociation does not occur (no peaks at $m / z 211 / 592$ ) since that would lead to formation of the $\mathrm{w}_{2}^{2-} / \mathrm{a}_{1}$ pair, which does not dissociate as easily, partly because it is not driven by the release of a Coulombic force, and partly because it is bound by a strong ion-induced dipole force. This is in full accord with the Rodgers/ Beauchamp mechanism.

Schemes $\mathbf{3}$ and $\mathbf{4}$ provide possible pathways for the

alternatively, the phosphate may attract a proton from the methylene group next to the connecting carbon, in which case elimination is accomplished through an E2B type mechanism (Cerny mechanism, upper part of Scheme 2). The cytosine situated at the $3^{\prime}$ end is less likely to be expelled in both $\mathrm{S}_{\mathrm{N}} 2$ and E2 mechanisms, since there is no phosphate attached to this side. But we further dissociations observed with the primary fragmentation products. The observed individual onsets of the fragments are given in Table 1. Each of the sequential dissociation steps has been verified in separate experiments in which the precursor ions were generated by in-source fragmentation and then brought to CID.<smiles></smiles>

$(\mathrm{C}-\mathrm{H})^{-}$

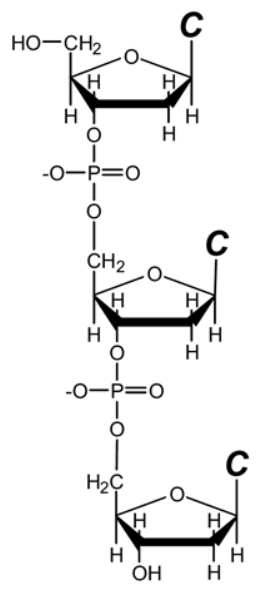

$(\mathrm{CCC}-2 \mathrm{H})^{2-}$

$m / z \quad 401.5$ $m / z 110$

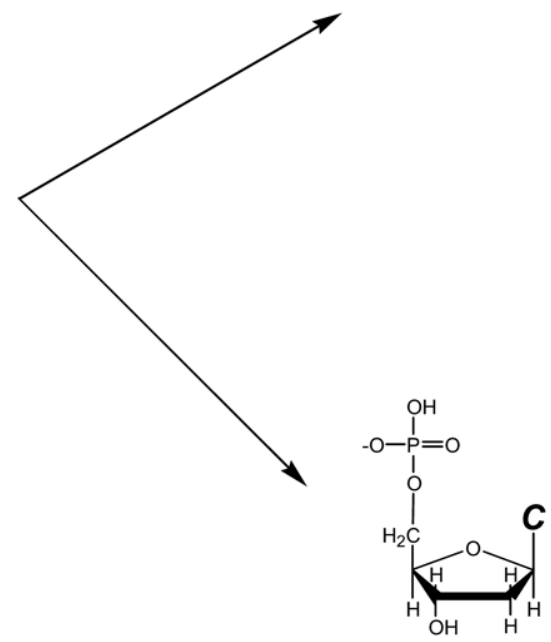

$$
\begin{gathered}
w_{1}^{-} \\
m / z \quad 306
\end{gathered}
$$



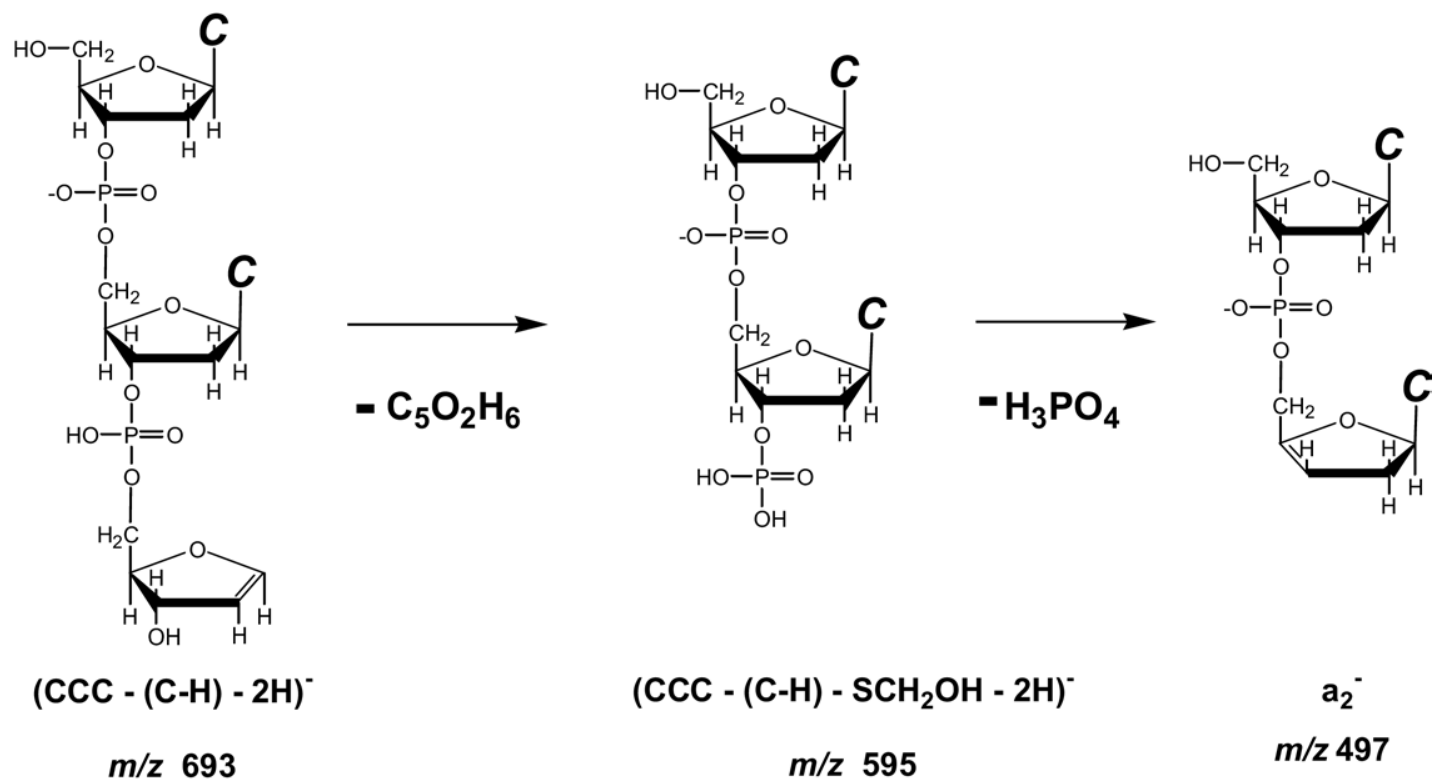

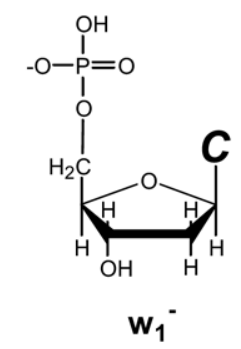

$m / z 306$
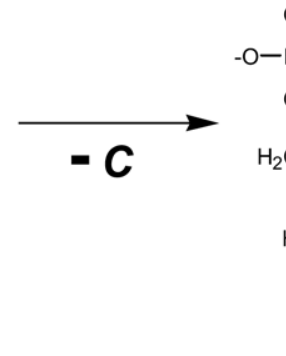

$m / z 19$
$\left(\mathrm{CCC}-(\mathrm{C}-\mathrm{H})-\mathrm{SCH}_{2} \mathrm{OH}-2 \mathrm{H}\right)^{-}$

$m / z 595$

\section{$\mathrm{a}_{2}{ }^{-}$ \\ $m / z 497$}

Scheme 4

\section{The Monoanion $(\mathrm{CCC}-\mathrm{H})^{-}$}

(a) Structural details. The two monoprotonated structures, in which the proton dissociated from the phosphate adjacent to the $5^{\prime}$ end and $3^{\prime}$ end, respectively, are both dominated by a strong hydrogen bond from the protonated phosphate group to the unprotonated (vide infra) (Figure 4). This interaction limits the effective conformational space for both structures. In addition to this central hydrogen bond, the nonprotonated phosphate effectively accepts hydrogen bonds from suitably situated hydrogen bond donors. In the case of protonation at the phosphate group closest to the $5^{\prime}$-terminusthe corresponding compound is denoted $\left(5^{\prime}\right)$ - the $3^{\prime}$ phosphate accepts hydrogen bonds from the protonated phosphate group as well as the two terminal OH groups. The same occurs for the $5^{\prime}$-phosphate in $3^{\prime}(\mathrm{CCC}-\mathrm{H})^{-}$ $\left(3^{\prime}\right)$ (see Figure 4).

(b) Pathways for collision induced dissociation. The collision induced dissociation of the monoanion, (CCC $\mathrm{H})^{-}$, was found to lead to the loss of cytosine as the primary dissociation event (Figure 5). In addition, there is signal corresponding to loss of furfuryl alcohol at slightly higher OV.
The loss of a neutral base is a typical primary dissociation event for lower charge states of oligonucleotides [3]. Habibi-Goudarzi and McLuckey [32] initially proposed two pathways to account for the $\left(a_{n}-B_{n}\right)$-ion formation, one initiated by neutral base loss, and the second initiated by loss of a nucleobase anion. In the first stage is partly liberated $(\mathrm{C}-\mathrm{H})^{-}$is formed probably following the mechanism illustrated in Scheme 2 . In the second stage a proton is abstracted from an available site in the close vicinity, probably from the neighboring phosphate group (Scheme 6, first part). If an excessive charge resides on the rest molecule there is not sufficient time to accommodate this proton transfer due to the quick relief of Coulombic strain, and the loss of the base as an anion is favored. For this reason, the loss of a neutral base is increasingly disfavored with increasing charge, in excellent agreement with the observations here.

The availability of a nearby acidic proton for transfer to $(\mathrm{C}-\mathrm{H})^{-}$, most likely the one located at the neighboring protonated phosphate group, is also a critical factor. H/D exchange experiments performed in solution indicated that there are nine exchangeable hydrogens in the structure of $(\mathrm{CCC}-\mathrm{H})^{-}$: a proton on one of 


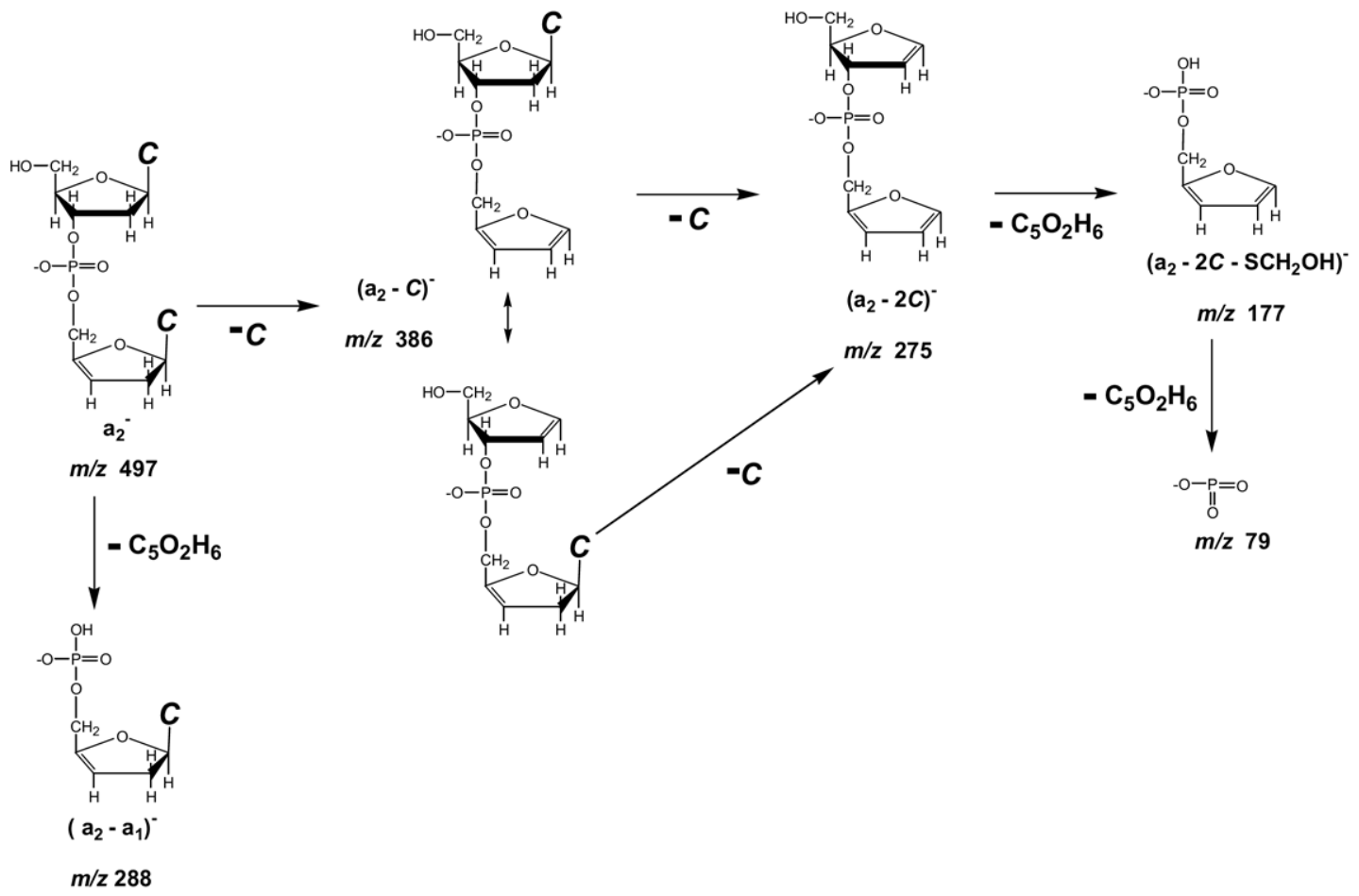

Scheme 5

the phosphates, two belonging to the end hydroxyl groups, and six to the primary amino groups of the cytosines. The CID fragmentation of the electrosprayed deuterated $(\mathrm{CCC}-\mathrm{H})^{-}$was found to be similar to that of the protonated species in that the primary dissociation event involved the loss of a neutral cytosine, however shifted to $114 \mathrm{u}$, which corresponds to a cytosine molecule containing three deuteriums. This observation confirms our interpretation. Barry et al. [33] have proposed a similar mechanism for the dissociation of short modified oligonucleotides.

\section{Successive Gas-Phase Protonation} of $(\mathrm{CCC}-2 \mathrm{H})^{2-}$

(a) Computational results. The enthalpy of protonation of the monophosphate $\mathrm{H}_{2} \mathrm{PO}_{4}^{-}$anion was estimated by
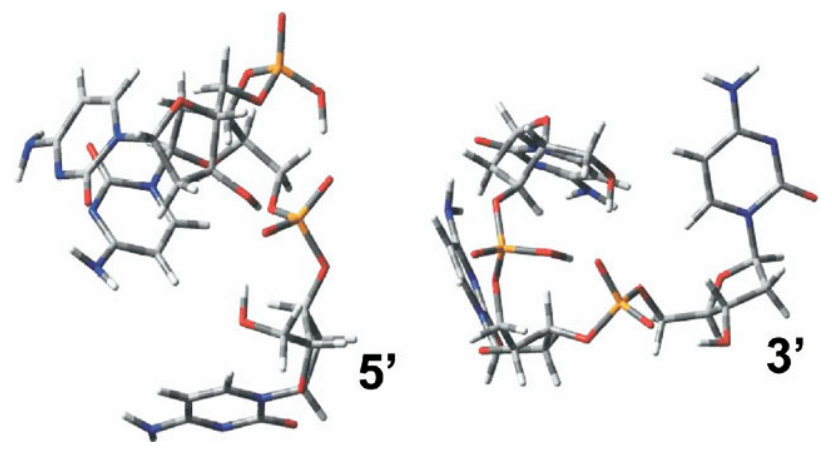

Figure 4. Minimum energy structures for CCC deprotonated at either the $3^{\prime}$ end (right) or the $5^{\prime}$ end (left). P, orange; $\mathrm{O}$, red; $\mathrm{N}$, blue; $\mathrm{C}$, grey; $\mathrm{H}$, white.
Morris et al. [34] using B3LYP/TZ2Pf + diffuse to be $P A=1370 \mathrm{~kJ} \mathrm{~mol}^{-1}$, in good agreement with their own experimental observation that the gas-phase acidity of phosphoric acid lies between those of $\mathrm{HCl}$ and $\mathrm{HBr}$ [35]. Our own theoretical estimates (Table 2) compare favorably with this finding and a very high level ab initio value of Alexeev et al. [36] of $P A=1376 \mathrm{~kJ} \mathrm{~mol}^{-1}$, compared to our "best" estimate (G3) of $P A=1376 \mathrm{~kJ}$ $\mathrm{mol}^{-1}$. The proton affinity seems to be quite unaffected by dimethylation; our calculations at the RI-MP2/ TZVPP level of theory indicate that $P A\left[\mathrm{H}_{2} \mathrm{PO}_{4}^{-}\right]=1388 \mathrm{~kJ}$ $\mathrm{mol}^{-1}$ and $P A\left[\left(\mathrm{CH}_{3} \mathrm{O}\right)_{2} \mathrm{PO}_{2}^{-}\right]=1390 \mathrm{~kJ} \mathrm{~mol}^{-1}$ (see Table 2). This computed value is in excellent agreement with a bracketed gas-phase acidity of $\mathrm{H}_{\text {acid }}^{\circ}\left[\left(\mathrm{CH}_{3} \mathrm{O}\right)_{2} \mathrm{PO}_{2} \mathrm{H}\right]=$

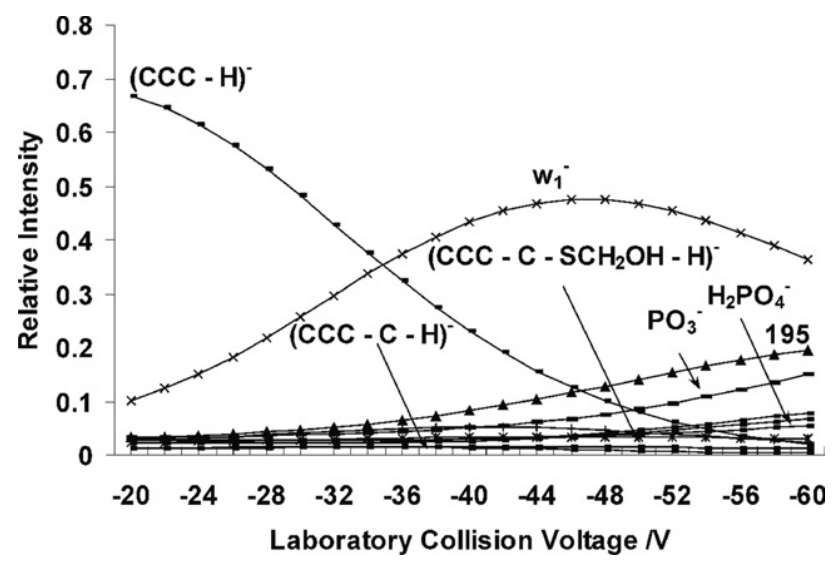

Figure 5. CID profiles for the dissociation of $(\mathrm{CCC}-\mathrm{H})^{-}$. Curves whose relative intensities were lower than 0.02 were not labeled. The structure of $\mathrm{m} / \mathrm{z} 195$ is presented in Scheme 4. 


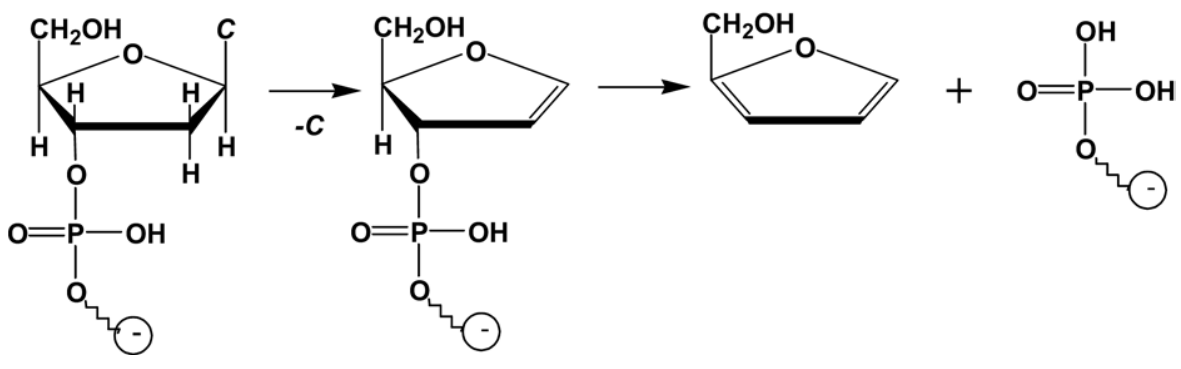

Scheme 6

$1389 \pm 17 \mathrm{~kJ} \mathrm{~mol}^{-1}$ determined experimentally using the flowing afterglow technique [37].

Table 2 also shows that the enthalpy of protonation of the dianion,

$$
(\mathrm{CCC}-2 \mathrm{H})^{2-}+\mathrm{H}^{+} \rightarrow(\mathrm{CCC}-\mathrm{H})^{-}
$$

is significantly higher than that for the protonation of the monoanion.

$$
(\mathrm{CCC}-\mathrm{H})^{-}+\mathrm{H}^{+} \rightarrow \mathrm{CCC}
$$

The corresponding calculated proton affinities (first protonation on the phosphate closest to the $5^{\prime}$ terminus) are $P A_{1}=1562 \mathrm{~kJ} \mathrm{~mol}^{-1}$ and $P A_{2}=1206 \mathrm{~kJ} \mathrm{~mol}^{-1}$, respectively (Table 2 ). Interestingly, the arithmetic mean of these two values, $\angle P A>=1384 \mathrm{~kJ} \mathrm{~mol}^{-1}$, is very close to those of the isolated phosphate groups in ${ }^{-} \mathrm{OP}(\mathrm{O})\left(\mathrm{OCH}_{3}\right)_{2}$ and $\left.{ }^{-} \mathrm{OP}(\mathrm{O})(\mathrm{OH})_{2}\right)$. We note that the aforementioned intraphosphate hydrogen bond can account for some of the difference $P A_{1}-\langle P A\rangle=178 \mathrm{~kJ}$ $\mathrm{mol}^{-1}$. An estimate of this interaction can be made by studying the dimer $\left(\mathrm{CH}_{3} \mathrm{O}\right)_{2}(\mathrm{O}) \mathrm{POH}{ }^{\cdots-} \mathrm{OP}(\mathrm{O})\left(\mathrm{OCH}_{3}\right)_{2}$. Dissociation of this dimer into its constituents is associated with a $B D E=124 \mathrm{~kJ} \mathrm{~mol}^{-1}$. Therefore, the difference $P A_{1}-<P A>$ cannot fully be accounted for only by the intraphosphate hydrogen. Within (CCC $2 \mathrm{H})^{2-}$ we note that most of the two negative charges are localized at each of the two phosphate groups. In terms of classical electrostatics this has the consequence that the molecule may be destabilized to Coulombic repulsion between the two charges. The corresponding repulsion in vacuum is $187 \mathrm{~kJ} \mathrm{~mol}^{-1}$ at a distance of 7.47 $\AA$ that, for convenience, we have set equal to the P-P distance. We are not aware of any accurate value for the dielectric constant of DNA. By assuming that the dielectric constant is in the range $\varepsilon=5-10$, Coulombic repulsion will be in the range $20-40 \mathrm{~kJ} \mathrm{~mol}^{-1}$.

(b) Results of the gas-phase reactivity measurements. The results of the computations predict that $\mathrm{HBr}$ (proton affinity of $\mathrm{Br}^{-}$at $298 \mathrm{~K}$ is $1354 \mathrm{~kJ} \mathrm{~mol}^{-1}$ [35] will protonate $(\mathrm{CCC}-2 \mathrm{H})^{2-}$ but not $(\mathrm{CCC}-\mathrm{H})^{-}$in the gas phase at room temperature. Indeed, experiments with the ESI/SIFT/QqQ tandem mass spectrometer indicated the occurrence of proton transfer from $\mathrm{HBr}$ to $(\mathrm{CCC}-2 \mathrm{H})^{2-}$, in competition with hydrobromination (see Figure 6):

$$
\begin{aligned}
& (\mathrm{CCC}-2 \mathrm{H})^{2-}+\mathrm{HBr} \rightarrow(\mathrm{CCC}-\mathrm{H})^{-}+\mathrm{Br}^{-} \\
& \rightarrow(\mathrm{CCC}-2 \mathrm{H})^{2-}(\mathrm{HBr})
\end{aligned}
$$

Reaction (eq 3) was seen to be rapid, $k=1.4 \times 10^{-9}$ $\mathrm{cm}^{3}$ molecule $\mathrm{s}^{-1}$, at room temperature with $22 \%$ of the reaction proceeding by the charge-separation channel (eq 3a) in which a proton is transferred from $\mathrm{HBr}$ to $(\mathrm{CCC}-2 \mathrm{H})^{2-}$. The high rate of proton transfer implies the absence of a substantial barrier to charge separation [38-40]. Therefore the exothermicity of this reaction, ca. $220 \mathrm{~kJ} \mathrm{~mol}^{-1}$, is sufficient for the Coulomb barrier that arises from the charge separation associated with the products to lie below the initial energy of the reactants.

The monoanion $(\mathrm{CCC}-\mathrm{H})^{-}$was shown in separate experiments, in which it was selected directly from the ESI source, to react with $\mathrm{HBr}$ by sequential hydrobro-

\begin{tabular}{|c|c|c|c|c|}
\hline Structure & $P A$ [RI-BP-86/SPV] & $P A$ [RI-MP2/TZVPP] & $P A[\mathrm{RI}-\mathrm{BP}-86 / \mathrm{TZVPP}]$ & $P A[G 3 @ 298 K]$ \\
\hline$\overline{(\mathrm{CCC}-2 \mathrm{H})^{2^{-}}}$ & $1586 / 1565^{* *}$ & $1562 / 1553 * *$ & & \\
\hline $5^{\prime}(\mathrm{CCC}-\mathrm{H})^{-}$ & 1229 & 1206 & & \\
\hline $3^{\prime}(\mathrm{CCC}-\mathrm{H})^{-}$ & 1250 & 1215 & & \\
\hline $\mathrm{H}_{2} \mathrm{PO}_{4}^{-}$ & 1425 & 1388 & 1385 & 1376 \\
\hline$\left(\mathrm{CH}_{3} \mathrm{O}\right)_{2} \mathrm{PO}_{2}^{-}$ & 1410 & 1390 & & \\
\hline
\end{tabular}
mination but not proton transfer (see Figure 6). The hydrobromination reaction (eq 4) was observed to be

Table 2. Proton affinities $\left(\mathrm{kJ} \mathrm{mol}^{-1}\right)$ at $298 \mathrm{~K}^{*}$

* Estimated at by including RI-BP-86/SPV zero point vibrational energies and adding $6.2 \mathrm{~kJ} \mathrm{~mol}^{-1}$ to account for the RT contribution to enthalpy plus difference in translational heat capacities.

** Former value for protonation at the phosphate closest to the $5^{\prime}$-terminus, the latter value for protonation at the phosphate closest to the $3^{\prime}$-terminus. 

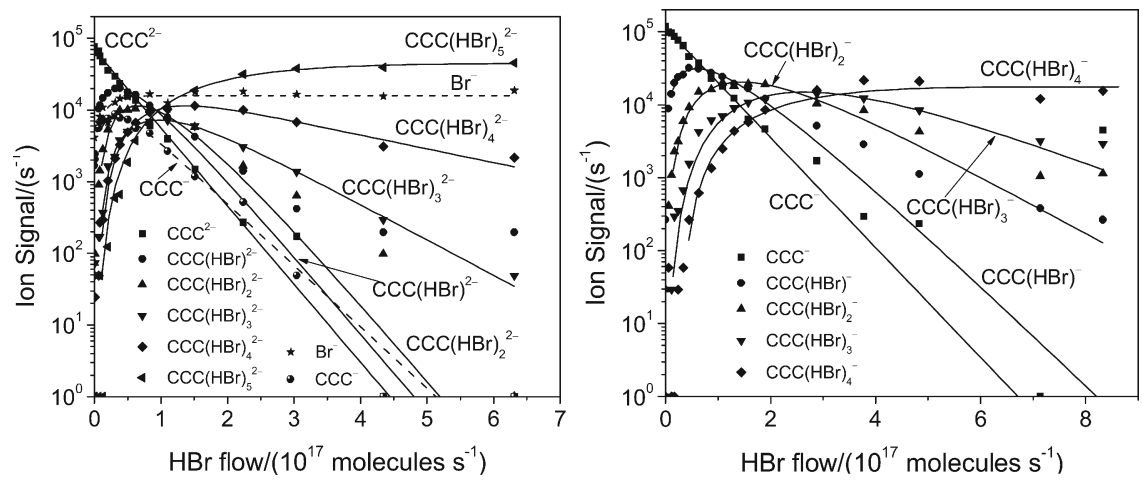

Figure 6. ESI/SIFT/QqQ results for the protonation and hydrobromination of $(\mathrm{CCC}-2 \mathrm{H})^{2-}(\mathrm{left}$ diagram) with $\mathrm{HBr}$ in helium buffer gas at $47 \pm 1 \mathrm{~Pa}$ and $292 \mathrm{~K},(\mathrm{CCC}-2 \mathrm{H})^{2-}$ is designated as $\mathrm{CCC}^{2-}$ and $(\mathrm{CCC}-\mathrm{H})^{-}$as $\mathrm{CCC}^{-}$. $(\mathrm{CCC}-\mathrm{H})^{-}$is shown in separate experiments to react further with $\mathrm{HBr}$ by sequential hydrobromination (right part).

fast and proceed with an effective bimolecular rate coefficient $k=7.1 \times 10^{-10} \mathrm{~cm}^{3}$ molecule $\mathrm{s}^{-1}$.

$$
(\mathrm{CCC}-\mathrm{H})^{-}+\mathrm{HBr} \rightarrow(\mathrm{CCC}-\mathrm{H})^{-}(\mathrm{HBr})
$$

This result is consistent with the computed proton affinities of the deprotonated phosphate in $(\mathrm{CCC}-\mathrm{H})^{-}$ near the $5^{\prime}$ terminus or the $3^{\prime}$ terminus (1229 and 1250 $\mathrm{kJ} \mathrm{mol}^{-1}$, respectively) that predict proton transfer from $\mathrm{HBr}$ to be endothermic by 125 and $104 \mathrm{~kJ} \mathrm{~mol}^{-1}$, respectively. To confirm this conclusion we selected $(\mathrm{CCC}-\mathrm{H})^{-}$from the ESI source anion and exposed it directly to the reaction with $\mathrm{HBr}$ (Figure 6).

The observed sequential hydrobromination recorded in Figure 6 is also interesting, especially as regards the number and sites of addition. The $(\mathrm{CCC}-2 \mathrm{H})^{2-}$ dianion was observed to add 5 molecules of $\mathrm{HBr}$ in rapid succession with higher-order effective bimolecular rate coefficients $\mathrm{k}>1 \times 10^{-9} \mathrm{~cm}^{3}$ molecule ${ }^{-1} \mathrm{~s}^{-1}$. The $(\mathrm{CCC}-\mathrm{H})^{-}$anion added $4 \mathrm{HBr}$ molecules sequentially with $\mathrm{k}>4 \times 10^{-10} \mathrm{~cm}^{3}$ molecule $\mathrm{e}^{-1} \mathrm{~s}^{-1}$. Presumably, all of these additions proceed by termolecular collisional stabilization with $\mathrm{He}$ acting as the third body, although bimolecular radiative stabilization cannot be ruled out since the experiments were not taken as a function of pressure.

So why five and four molecules, respectively? The sixth and fifth adducts, respectively, were looked for but not seen. We propose that $\mathrm{HBr}$ attaches to the most basic sites of the anions. According to the calculations by Green-Church and Limbach [41], and Pan et al. [42], the most basic sites on the $(\mathrm{CCC}-2 \mathrm{H})^{2-}$ are the negatively-charged phosphate groups, of which there are two, and the $\mathrm{N}_{3}$ position of the cytosines, of which there are three. This amounts to five potential sites for hydrobromination on $(\mathrm{CCC}-2 \mathrm{H})^{2-}$ and four sites on $(\mathrm{CCC}-\mathrm{H})^{-}$and would match the experimental observations if the other potential sites of the cytosines are insufficiently basic or become blocked with the addition of the first three on the cytosines. In a sense $\mathrm{HBr}$ provides a means of counting the most basic sites on deprotonated oligonucleotides. This is analogous to the previous use of $\mathrm{HI}$ to count basic sites in oligopeptide cations $[43,44]$.

\section{Conclusions}

We have explored, both experimentally and computationally, the gas-phase protonation of a relatively simple model of deprotonated DNA, the deprotonated trideoxynucleotide CCC, as well as the stability of the deprotonated CCC against collisional dissociation and its reactivity with $\mathrm{HBr}$, a potential proton donor.

The computed minimum energy gas-phase structures of the doubly and singly deprotonated CCC provide thermodynamic information for reprotonation and proved to be useful in the interpretation of the experimentally observed dissociation pathways of the doubly and singly deprotonated CCC.

The collision-induced dissociation of deprotonated CCC was observed to be charge-directed in that the dianion was seen to dissociate by charge separation via two competing channels, while the monoanion fragments exclusively by the loss of a neutral cytosine. Experiments performed with the deuterated analog of $(\mathrm{CCC}-\mathrm{H})^{-}$indicate that the mechanism of the neutral base elimination involves a transfer of a proton to the departing cytosine from the protonated phosphate group.

The experimental results obtained for the gas-phase chemical reactions of the deprotonated CCC with $\mathrm{HBr}$ provide a useful test of the thermochemical predictions of high-level calculations of large molecular ions and establish the feasibility of measuring the intrinsic chemistry of other, larger DNA-like anions.

The combination of theory, collision-induced dissociation, and reactivity measurements applied here to the singly and doubly deprotonated CCC trideoxynucleotide illustrate a useful approach for investigating similar biological molecular ions and learning more about the influence of charge state, number of repeating units, base composition, and conformation on 
gas-phase proton affinity, stability against dissociation, and chemical reactivity.

\section{Acknowledgments}

The authors greatly appreciate the continued financial support from the Natural Sciences and Engineering Research Council of Canada, the National Research Council, and MDS SCIEX. As holder of a Canada Research Chair in Physical Chemistry, DKB thanks the contributions of the Canada Research Chair Program to this research. EU thanks Professor Gernot Frenking and coworkers for hospitality, discussions, assistance, and computer resources during his sabbatical stay in Marburg.

\section{References}

1. Yamashita, M.; Fenn, J. B. Electrospray Ion Source. Another Variation on the Free-Jet Theme. J. Phys. Chem. 1984, 88, 4451-4459.

2. Fenn, J. B.; Manna, M.; Meng, C. K.; Wong, S. F. Electrospray IonizationPrinciples and Practice. Mass Spectrom. Rev. 1990, 9, 37-70.

3. Wu, J.; McLuckey, S. A. Gas-Phase Fragmentation of Oligonucleotide Ions. Int. I. Mass Spectrom. 2004, 237, 197-241.

4. Beck, J. L.; Colgrave, M. L.; Ralph, S. F.; Sheil, M. M. Electrospray Ionization Mass Spectrometry of Oligonucleotide Complexes with Drugs, Metals, and Proteins. Mass Spectrom. Rev. 2001, 20, 61-87.

5. Keller, K. M.; Brodbelt, J. S. Charge State-Dependent Fragmentation of Oligonucleotide/Metal Complexes. J. Am. Soc. Mass Spectrom. 2005, 16, 28-37.

6. Baker, E. S.; Bernstein, S. L.; Gabelica, V.; De Paw, E.; Bowers, M. T. G-Quadruplexes in Telomeric Repeats are Conserved in a Solvent-Free Environment. Int. J. Mass Spectrom. 2006, 253, 225-237.

7. Yang, J.; Håkansson, K. Fragmentation of Oligoribonucleotides from Gas-Phase Ion-Electron Reactions. J. Am. Soc. Mass Spectrom. 2006, 17, 1369-1375.

8. Hettich, R. L. Investigating the Effect of Transition Metal Ion Oxidation State on Oligodeoxyribonucleotide Binding by Matrix-Assisted Laser Desorption/Ionization Fourier Transform Ion Cyclotron Resonance Mass Spectrometry. Int. J. Mass Spectrom. 2001, 204, 55-75.

9. Monn, S. T. M.; Schürch, S. Investigation of Metal-Oligonucleotide Complexes by Nanoelectrospray Tandem Mass Spectrometry in the Positive Mode. J. Am. Soc. Mass Spectrom. 2005, 16, 370-378.

10. Pan, S.; Sun, X. S. P.; Lee, J. K. DNA. Stability in the Gas versus Solution Phases: A Systematic Study of Thirty-One Duplexes with Varying Length, Sequence, and Charge Level. J. Am. Soc. Mass Spectrom. 2006, 17, 1383-1395

11. Bayer, E.; Gforer, P.; Rentel, C. Coordination-Ionspray-MS (CIS-MS), a Universal Detection and Characterization Method for Direct Coupling with Separation Techniques. Angew. Chem. Int. Ed. 1999, 38, 992-995.

12. Eichhorn, G. L. The Effects of Metal Ions on the Structure and Function of Nucleic Acids. In Metal Ions in Generic Information Transfer, Eichhorn G. L., Marzilli, L. G., Eds.; Elsevier: New York, 1981; pp. 1-46.

13. Aoki, K. Metal Binding Effects on Nucleic Acid Structures. In Comprehensive Supramolecular Chemistry, Atwood, J. L., Davies, J. E. D., Macnicol, D. D., Vogtle F., Eds.; Elsevier Pergamon: New York, 1996; pp. 249-294.

14. Hud, N. V.; Polak, M. DNA-Cation Interactions: The Major and Minor Grooves are Flexible Ionophores. Curr. Opin. Sruct. Biol. 2001, 11, 293-301.

15. Davis, J. T. G-Quartets 40 Years Later: From 5'-GMP to Molecular Biology and Supramolecular Chemistry. Angew. Chem. Int. Ed. 2004, 43, 668-698.

16. Koyanagi, G. K.; Baranov, V. I.; Tanner, S. D.; Anichina, J.; Jarvis, M. J. Y.; Feil, S.; Bohme, D. K. A Novel Chemical Reactor Suited for Studies of Biophysical Chemistry: Construction and Evaluation of a Selected Ion Flow Tube Utilizing an Electrospray Ion Source and a Triple Quadrupole Detection System. Int. J. Mass Spectrom. 2007, 265(2/ 3), 295-301.

17. Case, D.; Darden, T.; Gohlke, H.; Luo, R.; Merz, K. M. Jr.; Onufriev, A.; Simmerling, C.; Wang, B.; Woods, R. The Amber Biomolecular Simulation Program. J. Comput. Chem. 2005, 26, 1668-1688.

18. Cheatham T. E. III; Young, M. A. Molecular Dynamics. Simulation of Nucleic Acids: Successes, Limitations, and Promise. Biopolymers 2001, 56, 232-256.

19. Stewart, J. J. P. PM3. In Encyclopedia of Computational Chemistry, Vol. II, Clark, T., Ed.; John Wiley and Sons, New York, 1998

20. Eichkorn, K.; Weigend, F.; Treutler, O.; Ahlrichs, R. Auxiliary Basis Sets for Main Row Atoms and Transition Metals and Their Use to Approximate Coulomb Potentials. Theoretical Chemistry Accounts: Theory, Computation, and Modeling. Theor. Chim. Acta. 1997, 97, 119-124.
21. Schäfer, A.; Horn, H.; Ahlrichs, R. Fully Optimized Contracted Gaussian Basis Sets for Atoms Li to Kr. J. Chem. Phys. 1992, 97, 2571-2577.

22. Becke, A. D. Density-Functional Exchange-Energy Approximation with Correct Asymptotic Behavior. Phys. Rev. A 1988, 38, 3098-4000.

23. Perdew, J. P. Density-Functional approximation for the Correlation Energy of the Inhomogeneous Electron Gas. Phys. Rev. B 1986, 33, 8822-8824.

24. Weigend, F.; Haser, M.; Patzelt, H.; Ahlrichs, R. RI-MP2: Optimized Auxiliary Basis Sets and Demonstration of Efficiency. Chem. Phys. Lett. 1998, 294, 143-152.

25. Weigend, F.; Häser, M. RI-MP2: First Derivatives and Global Consistency. Theor. Chim. Acta. 1997, 97, 331-340.

26. Frisch, M. J.; Trucks, G. W.; Schlegel, H. B.; Scuseria, G. E.; Robb, M. A. Cheeseman, J. R.; Montgomery, J. A. Jr.; Vreven, T.; Kudin, K. N.; Burant, J. C.; Millam, J. M.; Iyengar, S. S.; Tomasi, J.; Barone, V.; Mennucci, B.; Cossi, M.; Scalmani, G.; Rega, N.; Petersson, G. A.; Nakatsuji, H.; Hada, M.; Ehara M.; Toyota, K.; Fukuda, R.; Hasegawa, J.; Ishida, M.; Nakajima, T.; Honda, Y.; Kitao, O.; Nakai, H.; Klene, M.; Li, X.; Knox, J. E.; Hratchian, H. P.; Cross, J. B.; Bakken, V.; Adamo, C.; Jaramillo, J.; Gomperts, R.; Stratmann, R. E.; Yazyev, O.; Austin, A. J.; Cammi, R.; Pomelli, C.; Ochterski, J. W. Ayala, P. Y.; Morokuma, K.; Voth, G. A.; Salvador, P.; Dannenberg, J. J.; Zakrzewski, V. G.; Dapprich, S.; Daniels, A. D.; Strain, M. C.; Strain, O.; Farkas, O.; Malick, D. K.; Rabuck, A. D.; Raghavachari, K.; Foresman, J. B.; Ortiz, J. V.; Cui, Q.; Baboul, A. G.; Clifford, S.; Cioslowski, J.; Stefanov, B. B. Liu, G.; Liashenko, A.; Piskorz, P.; Komaromi, I.; Martin, R. L.; Fox, D. J.; Keith, T.; Al-Laham, M. A.; Peng, C. Y.; Nanayakkara, A.; Challacombe, M.; Gill, P. M. W.; Johnson, B.; Chen, W.; Wong, M. W.; Gonzalez, C.; Pople, J. A. Gaussian 03, Gaussian, Inc.: Wallingford CT, 2004.

27. Ahlrichs, R.; Baer, M.; Haser, M.; Horn, H.; Kolmel, C. Electronic Structure Calculations on Workstation Computers: The Program System TURBOMOLE. Chem. Phys. Lett. 1989, 162, 165-169.

28. Curtiss, L. A.; Raghavachari, K.; Redfern, P. C.; Rassolov, V.; Pople, J. A Gaussian-3 (G3) Theory for Molecules Containing First and SecondRow Atoms. J. Chem. Phys. 1998, 109, 7764-7776.

29. Wan, K. X.; Gross, J.; Hillenkamp, F.; Gross, M. L. Fragmentation Mechanisms of Oligodeoxynucleotides Studied by H/D Exchange and Electrospray Ionization Tandem Mass Spectrometry. J. Am. Soc. Mass Spectrom. 2001, 12, 193-205.

30. Cerny, R. L.; Gross, M. L.; Grotjahn, L. Fast Atom Bombardmen Combined with Tandem Mass Spectrometry for the Study of Dinucleotides. Anal. Biochem. 1986, 156, 424-435.

31. Rogers, M. T.; Campbell, S.; Marzluff, E. M.; Beauchamp, J. L. LowEnergy Collision-Induced Dissociation of Deprotonated Dinucleotides: Determination of the Energetically Favored Dissociation Pathways and the Relative Acidities of the Nucleic Bases. Int. J. Mass Spectrom. Ion Processes 1994, 137, 121-149.

32. Habibi-Goudarzi, S.; McLuckey, S. A. Ion Trap Collisional Activation of the Deprotonated Deoxymononucleoside and Deoxydinucleoside Monophosphates. J. Am. Soc. Mass Spectrom. 1995, 6, 102-113.

33. Barry, J. P.; Vouros, P.; Van Schepdael, A.; Law, S.-J. Mass and Sequence Verification of Modified Oligonucleotides Using Electrospray Tandem Mass Spectrometry. J. Mass Spectrom. 1995, 30, 993-1006.

34. Morris, R. A.; Knighton, W. B.; Viggiano, A. A.; Hoffman, B. C. Schaeffer, H. F. III. The Gas-Phase Acidity of $\mathrm{H}_{3} \mathrm{PO}_{4}$. J. Chem. Phys. 1997, 106, 3545-3547.

35. NIST Standard Reference Database. Number 69, June 2005 Release. Negative Ion Energetics Data Compiled by Bartmess, J. E. http:// webbook.nist.gov/chemistry.

36. Alexeev, Y.; Windus, T. L.; Zhan, C.-G., Dixon, D. A. Accurate Heats of Formation and Acidities for $\mathrm{H}_{3} \mathrm{PO}_{4}, \mathrm{H}_{2} \mathrm{SO}_{4}$, and $\mathrm{H}_{2} \mathrm{CO}_{3}$ from ab Initio Electronic Structure Calculations. Int. J. Quant. Chem. 2005, 102, 775-784.

37. Lum, R. C.; Grabowski, J. J. Trimethyl Phosphate: The Intrinsic Reactivity of Carbon versus Phosphorus Sites with Anionic Nucleophiles. J. Am. Chem. Soc. 1992, 114, 8619-8627.

38. Petrie, S.; Javahery, G.; Wang, J.; Bohme, D. K. A SIFT Study of Charge Transfer from Fullerene Dications: "Bracketing" the Second Ionization Energies of $C_{60}$ and $C_{70}$. J. Phys. Chem. 1992, 96, 6121-6123.

39. Petrie, S.; Javahery, G.; Bohme, D. K. First Steps Towards an "Effective Gas-Phase Acidity" Ladder for Derivatized Fullerene Dications. Int. I. Mass Spectrom. Ion Processes 1993, 124, 145-456.

40. Javahery, G.; Petrie, S.; Wincel, H.; Bohme, D. K. Experimental Study of Reactions of Buckminsterfullerene Cations $\mathrm{C}_{60}{ }^{+}, \mathrm{C}_{60}{ }^{+}$, and $\mathrm{C}_{60}{ }^{\cdot 3+}$ with Ammonia and Amines in the Gas Phase. J. Am. Chem. Soc. 1993, 115, 6295-6301.

41. Green-Church, K. B.; Limbach, P. A. Mononucleotide Gas-Phase Proton Affinities Determined by the Kinetic Method. J. Am. Soc. Mass Spectrom. 2000, 11, 24-32.

42. Pan, S.; Verhoeven, K.; Lee, J. K. Investigation of the Initial Fragmentation of Oligodeoxynucleotides in a Quadrupole Ion Trap: Charge Level-Related Base Loss. J. Am. Soc. Mass Spectrom. 2005, 16, 1853-1865.

43. Stephenson, J. L.; McLuckey, S. A. Counting Basic Sites in Oligopeptides via Gas-Phase Ion Chemistry. Anal. Chem. 1997, 69, 281-285.

44. Stephenson, J. L.; McLuckey, S. A. Gaseous Protein Cations are Amphoteric. J. Am. Chem. Soc. 1997, 119, 1688-1696. 